\title{
Case report. 71-jarige man met progressieve onderbuikspijn en onvermogen tot mictie
}

\author{
Jolien T. M. Mensink · Frank M. Zijta · Tan Q. T. Tong
}

Geaccepteerd op: 14 april 2021 / Published online: 5 mei 2021

(C) The Author(s) 2021

Samenvatting Deze casus beschrijft een patiënt met progressieve onderbuikspijn en onvermogen tot mictie op basis van een uitzonderlijk grote mediane intraprostatische cyste. Een dergelijke cyste is een zeldzame, benigne, vaak asymptomatische aandoening en kan onderverdeeld worden in een utriculus cyste en een Müllerian duct cyste. Na drainage van de cyste bleef de patiënt in deze beschreven casus klachtenvrij.

Trefwoorden prostaatcyste $\cdot$ benigne $\cdot$ congenitaal

Case report. 71 year old man with progressive abdominal pain and acute urinary retention

\begin{abstract}
In this case report we discuss a patient with progressive abdominal pain and a urinary retention based on an extraordinary presentation of a median intraprostatic cyst. Such a cyst is a benign, mostly asymptomatic cyst which can be divided in a utriculus cyst and an Müllerian duct cyst. The patient in this case was treated by aspiration and was symptom-free thereafter.
\end{abstract}

Keywords prostatic cyst · benign · congenital

\section{Introductie}

Cysten in de lage urinewegen van de man zijn zeldzaam met een beschreven incidentie van ongeveer $1 \%$

drs. J. T. M. Mensink ( $\varangle)$ · drs. T. Q. T. Tong

afdeling Urologie, Haaglanden Medisch Centrum, Den Haag,

Nederland

jolienmensink@hotmail.com

dr. F. M. Zijta

afdeling Radiologie, Haaglanden Medisch Centrum, Den Haag, Nederland
$[1,2]$. Bij patiënten met plasklachten loopt de beschreven incidentie op tot $5 \%[3,4]$. Het merendeel van de patiënten is asymptomatisch waardoor de incidentie vermoedelijk onderschat wordt [5]. De literatuur hierover bestaat vooral uit case reports $[4,5]$. Wij beschrijven een patiënt die zich presenteerde met een symptomatische grote cyste die uitging van de lage urinewegen.

Utriculuscyste van de prostaat of Müllerian duct cyste

- Utriculus cyste:

- embryologisch overblijfsel van de buizen van Müller [1];

- craniale begrenzing reikt meestal niet uit boven de basis van de prostaat [1];

- anatomisch verbonden met de urethra prostatica, de ductus ejaculatorius en de vesica seminalis [1];

- MRI: hoog signaal op de T2-gewogen series [1];

- geassocieerd met aangeboren urogenitale afwijkingen, zoals hypospadie, seksuele differentiatiestoornissen, cryptorchisme en ipsilaterale renale agnesie [6].

- Müllerian duct cyste:

- ten gevolge van een onvolledige regressie en door een sacculaire dilatatie van de buizen van Müller [6];

- veelal groter dan de utriculus cyste [1];

- bevat nooit spermatozoa maar wel regelmatig stenen [1];

- geen verbinding met de urethra prostatica [1];

- MRI: hoog signaal op de T2-gewogen series [1];

- geassocieerd met renale agenesie, niet met andere aangeboren urogenitale afwijkingen [6]. 


\section{Casus}

Een 71-jarige man presenteerde zich op de Spoedeisende Hulp (SEH) met progressieve onderbuikspijn en acuut onvermogen tot mictie. Er werd een transurethrale katheter (TUC) geplaatst, waaruit $700 \mathrm{ml}$ heldere urine afliep en waarna de buikpijn significant afnam. De niet-urologische voorgeschiedenis betrof hypertensie en een arachnoïdale cyste rechts temporaal. Anamnestisch bleek de patiënt al enkele jaren milde, onbehandelde, progressieve klachten van aandrang te hebben. Het urinesediment toonde, behoudens 13 leukocyten en 209 erytrocyten, geen afwijkingen. Er werd geen bloed- of radiologisch onderzoek verricht. De patiënt werd ontslagen met een afspraak op de polikliniek urologie.

Twee dagen later presenteerde de patiënt zich opnieuw op de SEH, met progressieve onderbuikspijn en obstipatie. Hij gaf aan al enkele maanden moeizame ontlasting te hebben; de laatste ontlasting was vier dagen voor presentatie op de SEH. De TUC liep goed af.

Bij lichamelijk onderzoek werd alleen drukpijn links onderin de buik gevonden. Bij rectaal toucher werden hemorroïden en een vergrote prostaat geconstateerd. De laboratoriumuitslag vermeldde $\mathrm{Hb} 9,4$, leukocyten 8,3 en CRP 12. Radiologisch onderzoek werd niet verricht. Er werd gestart met laxantia en er werd een poliklinische colonoscopie ingepland met analyse door een MDL-arts.

Drie dagen later presenteerde de patiënt zich vervroegd op de poli Urologie met veel blaaskrampen bij een goed aflopende TUC met heldere urine. Bij lichamelijk onderzoek zagen wij een bolle, gespannen buik. Echografisch werd het beeld van een urineretentie gezien, waarbij de ballon van de katheter achter de blaas was gelegen. Na vergeefse pogingen tot transurethrale repositionering, werd echogeleid een suprapubische katheter (SPC) geplaatst; waaruit binnen 2 uur 1 liter sanguinolent vocht afliep met een kreati-

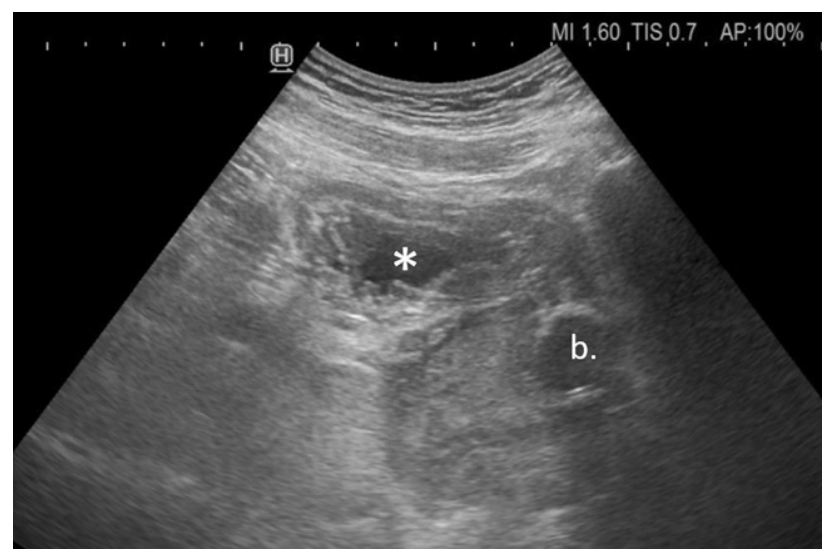

Figuur 1 Samengevallen urineblaas $\left({ }^{*}\right)$ met uitgebreide trabeculatie. Posterolateraal van de samengevallen urineblaas is de opgeblazen ballon zichtbaar (b.). De SPC is herkenbaar. Dit bevestigt de extravesicale positie van de drain ninewaarde van 600 umol. De serumwaarde van het kreatinine was $132 \mathrm{umol}$ en het vocht betrof dus geen $100 \%$ urine. Er werd geen aanvullend laboratoriumonderzoek ingezet.

Vanwege klinische verdenking op extravesicale positionering van de SPC of positionering in een blaasdivertikel met nauwe divertikelhals, werd echografisch onderzoek op de polikliniek Radiologie uitgevoerd. Dit onderzoek bevestigde extravesicale plaatsing (fig. 1). Op de aanvullend gemaakte CT-scan was daarnaast in het kleine bekken uitgebreide extraperitoneale hematoomvorming $(56 \times 70 \times 64 \mathrm{~mm})$ links paramediaan te zien. Er was geen letsel te zien van omliggende structuren en ook waren geen intraperitoneale afwijkingen te zien.

Wegens persisterende pijnklachten werd de patiënt opgenomen ter observatie. Tijdens opname werd een cystoscopie uitgevoerd waarbij zowel blaasletsel, blaasdivertikel als blaasmalformatie werd uitgesloten. Intravesicaal werd geen SPC gezien. Wel was er een opvallende kleine blaascapaciteit van slechts ongeveer $100 \mathrm{ml}$.

Nadat de SPC niet langer productief was, werd deze verwijderd.

Uit aanvullend laboratoriumonderzoek bleek het prostaatspecifiek antigeen (PSA) verhoogd (PSA 109).

$\mathrm{Na}$ twee dagen verliet de patiënt het ziekenhuis pijnvrij met een probleemloze spontane mictie.

Vanwege het verhoogde PSA werd 36 dagen na de eerste presentatie, poliklinisch een MRI-prostaat verricht. De MRI liet een grote cysteuze laesie zien $(130 \times 80 \times 100 \mathrm{~mm})$ met caudaal een midline tubulaire structuur die doorliep tot in de prostaat, posterieur van de urethra tot aan het verumontanum. Caudaal in de cysteuze afwijking waren debris en schotten zichtbaar met een intermediair signaal op T2 en een intermediaire diffusierestrictie in het kader van een traumatische SPC-plaatsing in deze cysteuze laesie, met residuale bloedproducten. Er werd geen verbinding aangetoond tussen de cyste en de blaas, maar wel een sterke verplaatsing van de blaas en prostaat naar rechts door massawerking (fig. 2a). De prostaat had een volume van $39 \mathrm{cc}$ en werd beoordeeld als een PIRADS 2.

In de follow-up daalde het PSA spontaan naar 10,2 en vervolgens naar 5,0, zodat de differentiaaldiagnose van prostaatcarcinoom werd verworpen. Omdat de cysteuze vochtcollectie na het aanprikken groter werd, werd in het multidisciplinair overleg besloten tot chirurgische verwijdering van de mediane prostaatcyste.

In de wachttijd tot de operatie verdwenen de klachten van de patiënt. Op de controle-MRI bleek het volume van de cysteuze structuur duidelijk afgenomen (fig. 2b). In samenspraak met de patiënt werd op grond daarvan afgezien van de ingreep. 

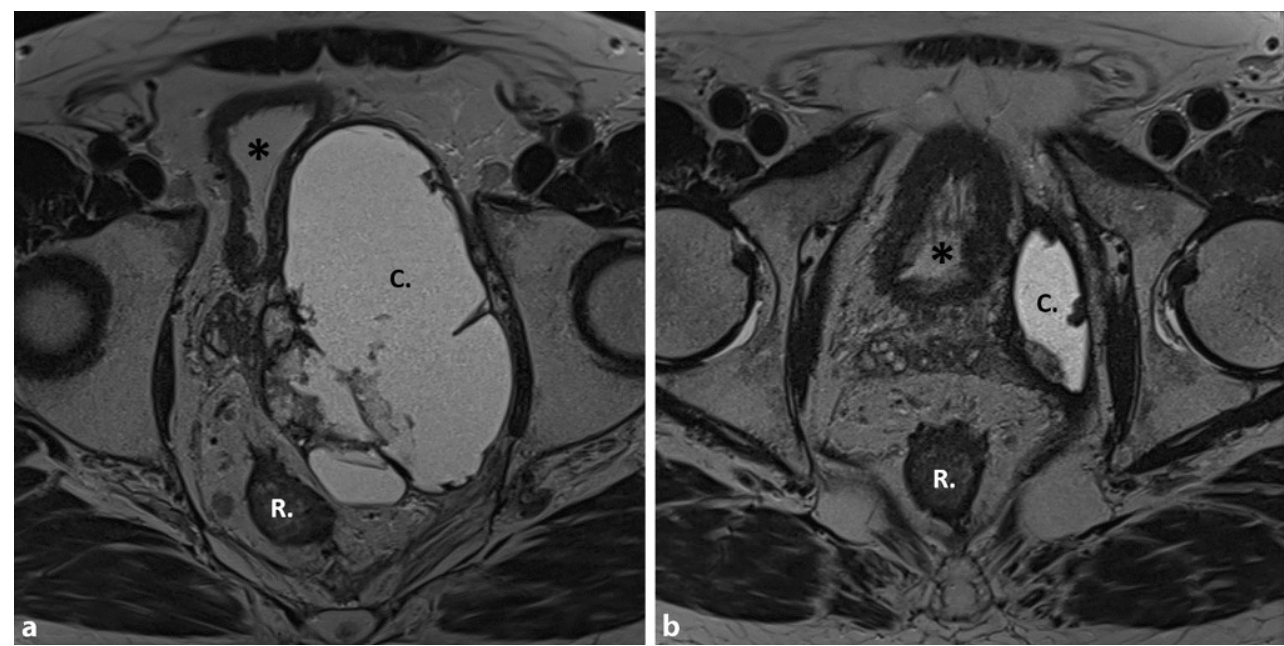

Figuur 2 a Axiale T2 TSE MRI. Grote, pre-existente thans hemorragisch veranderde cysteuze structuur $(130 \times 80 \times 100 \mathrm{~mm})($ C. $)$ met debris en schotten. Er is begeleidende massawerking op omliggende viscerale structuren, namelijk blaas $\left({ }^{*}\right)$ en rectum $(R$.) b Axiale T2 TSE MRI. Op de

\section{Discussie}

Cysten in de lage urinewegen van de man zijn zeldzaam en meestal asymptomatisch [1]. Verschillende congenitale urogenitale afwijkingen zoals hypospadie, stoornissen in de geslachtsontwikkeling (DSD), cryptorchisme en unilaterale renale agenesie zijn geassocieerd met cysten van de lage urinewegen bij mannen [6]. De patiënt in deze casus had geen congenitale urogenitale afwijkingen en ook in zijn familie kwamen geen urogenitale afwijkingen voor.

Bij grote cysteuze volumes zijn symptomen beschreven als (recidiverende) urineweginfecties, pijnklachten, (recidiverende) epididymitis, prostatitis, hematospermie, buikpijn, infertiliteit en acute urineretentie [5, 7].

Maligne ontaarding is zeer zeldzaam: slechts in twee case reports is maligne ontaarding van prostaatutriculus cysten in heldercellig adenocarcinoom of plaveiselcelcarcinoom beschreven [8, 9].

Op grond van de PSA-daling was een adenocarcinoom in deze casus zeer onwaarschijnlijk en op de MRI werden geen aanwijzingen voor een maligniteit gevonden.

Er bestaan verschillende theorieën over het ontstaan van de mediane prostaatcyste. Een ervan veronderstelt dat de mediane prostaatcyste een embryologisch overblijfsel is van de buizen van Müller [1]. Vroeg in de embryonale fase beschikken beide geslachten over de buizen van Müller en de buizen van Wolf. De buizen van Müller gaan bij mannelijke embryo's in regressie onder invloed van anti-Müller-hormoon (AMH) geproduceerd door de sertolicellen. Als dit proces van regressie onvolledig verloopt, is sprake van een embryologisch overblijfsel; een cyste [6].

Shebel et al. onderscheiden drie type cysten van de lage urinewegen van de man: intraprostatische cys-
controle-MRI na drie maanden is een evidente afname te zien van de cysteuze structuur links paramediaan in het kleine bekken $(50 \times 20 \times 30 \mathrm{~mm})$. Er is een vrijwel normale positie van de viscerale midlinestructuren

ten, extraprostatische cysten en mimics of prostatic and periprostatic cysts (zoals een gedilateerde zaadblaas) [1]. In deze casus is sprake van een intraprostatische mediane cyste, die kan worden onderverdeeld in de utriculuscyste of een müllerian duct cyste.

In de differentiaaldiagnose van de mediane prostaatcyste staan het blaasdivertikel en de vesicula seminalis cyste. In de literatuur worden verschillende onderzoeken beschreven voor het stellen van de diagnose, zoals een transurethrale echo van de prostaat (TRUS), een MRI-prostaat of een cystoscopie.

Behandeling van de mediane prostaatcyste is alleen geïndiceerd bij symptomatische patiënten. Er zijn verschillende behandelopties;

- aspiratie (transperineaal of transrectaal), eventueel gevolgd door scleroseren $[1,5,10,11]$;

- transurethrale deroofing of incisie $[1,5,11]$;

- chirurgische resectie (open of laparoscopisch, transperitoneaal, retropubisch of extravesicaal) $[1,4,5$, 11];

- marsupialisatie $[3,5,11]$.

Er is geen eenduidige behandeling beschreven voor cysten in de lage urinewegen. In deze casus werd bij de eerste presentatie onbedoeld een drainage van de cyste uitgevoerd, bij onjuiste diagnose. In de weinige case reports die er zijn, wordt gesuggereerd dat een hernieuwde aspiratie slechts zelden noodzakelijk is [11]. De cyste in deze casus liep initieel na aspiratie weer vol. Het volume van de cyste was bij eerste presentatie $56 \times 70 \times 64 \mathrm{~mm}$ op de CT-scan, maar bleek 36 dagen na de aspiratie toegenomen te zijn tot $130 \times 80 \times 100 \mathrm{~mm}$ (MRI-scan). Bij een controleMRI na drie maanden bleek het volume van de cyste zonder verdere interventies evident afgenomen te zijn $(50 \times 20 \times 30 \mathrm{~mm})$. 


\section{Conclusie}

De mediane intraprostatische cyste is een goedaardige congenitale cyste bij mannen, die waarschijnlijk ontstaat tijdens de embryogenese. De bijzondere grootte van de cyste leidde bij deze patiënt tot mictie- en defecatieproblemen. De TUC werd initieel goed gepositioneerd, maar door het volume van de cyste onjuist als incorrecte plaatsing geïnterpreteerd. Vervolgens werd de cyste onbedoeld gedraineerd door een poging een SPC te plaatsen. Behandeling van de mediane intraprostatische cyste is geïndiceerd bij symptomatische patiënten. In de literatuur worden aspiratie en deroofing als behandelopties bij kleine cystes beschreven. Mogelijk kan ook bij een grotere cyste worden volstaan met aspiratie.

Open Access This article is distributed under the terms of the Creative Commons Attribution 4.0 International License (http://creativecommons.org/licenses/by/4.0/), which permits unrestricted use, distribution, and reproduction in any medium, provided you give appropriate credit to the original author(s) and the source, provide a link to the Creative Commons license, and indicate if changes were made.

\section{Literatuur}

1. Shebel HM, Farg HM, Kolokythas O, El-Diasty T. Cysts of the lower male genitourinary tract: embryologic and anatomic considerations and differential diagnosis. Radiographics. 2013;33(4):1125-43.

2. Moore RA. Pathology of the prostatic utricle. Arch Pathol. 1937;23:517-24.
3. DikP, LockT, Schrier B, Zeijlemaker B, Boon T. Transurethral marsupialization of a medial prostatic cyst in patients with prostatitis-like symptoms. J Urol. 1996;155(4):1301-4.

4. Jaidane M, Hidoussi A, Slama A, Hmida W, Sorba NB, Mosbah F. An acute urinary retention in an old man caused by a giant Müllerian duct cyst: a case report. Cases J. 2009;2:203.

5. Al-Nasser KA, Almannie RM. New technique for the management of anteriorlylocated midline prostatic cysts causing severe lower urinary tract symptoms: Case report and literature review. Int J Surg Case Rep. 2019;55:107-11.

6. Trigaux JP, Van Beers B, Delchambre F. Male genital tract malformations associated with ipsilateral renal agenesis: sonographic findings. JClin Ultrasound. 1991;19(1):3-10.

7. Ishikawa M, Okabe H, Oya T, et al. Midline prostatic cysts in healthy men: incidence and transabdominal sonographic findings. AJRAm J Roentgenol. 2003;181:1669-72.

8. Zhang C, Li X, He Z, Xiao Y, Li S, Zhou L. Squamous cell carcinoma of the enlarged prostatic utricle in an adult. Urology. 2012;79(2):23-4.

9. Gualco G, Ortega V, Ardao G, Cravioto F. Clear cell adenocarcinoma of the prostatic utricle in an adolescent. Ann Diagn Pathol. 2005;9(3):153-6.

10. Saito $S$. Transrectal ultrasound-guided puncture, drainage, andminocyclinehydrochloridesclerotherapy for thesymptomatic prostatic cyst. JEndourol. 2002;16(9):693-5.

11. Coppens L, Bonnet P, Andrianne R, Leval J de. Adult Müllerian duct or utricle cyst: clinical significance and therapeutic management of 65 cases. JUrol. 2002;167(4):1740-4.

drs. Jolien T.M. Mensink, anios urologie

dr. Frank M. Zijta, radioloog

drs. Tan Q.T. Tong, uroloog 